\title{
O fundo de vingança da Penologia Moderna (*)
}

\section{Noé Azevedo}

O tema desta palestra foi inspirado por dois livros recentes: "Actualidad de la Venganza", de Mariano RuizFunes (Buenos Aires, fevereiro de 1944) e "New Horizons in Criminology", de Barnes and Teeters (Nova York, março de 1944.)

Ambos constituem libelọs tremendos contra a pena, um, contra a pena em geral, e o outro, encarando especialmente a pena de prisão.

O assunto há de interessar especialmente ao nosso douto colega Prof. Ataliba Nogueira, autor da conhecida monografia "Pena sem Prisão", onde se mostra inimigo das penitenciárias mas, desafortunadamente, adepto das penas, e de penas severíssimas, assumindo uma atitude doutrinária inteiramente em oposição com os impulsos do seu coração boníssimo, como deu mostras no Conselho Penitenciário, onde ninguém o superava nos votos favoráveis a livramentos condicionais e a pedidos de perdão.

Um dos mais doutos representantes do Ministério Público na Capital e livre-docente desta casa, em um primoroso discurso, no qual, todavia, apareciam alguns laivos de ironia, deu-me a honra de chamar o nosso Dorado Montero. Realmente, há um quarto de século, venho seguindo, nos estudos de direito penal, a orientação do originalíssimo pro-

(*) Preleção proferida na solenidade do encerramento dos cursos, na Faculdade de Direito da Universidade de São Paulo, em 14 de novembro de 1944 . 
fessor de Salamanca, autor de "El Derecho Protector de los Criminales", que Jiménez de Asúa considera um pensador genial e seu mestre, apesar de não ter tido a ventura de ser seu aluno.

Será utópica essa concepção de um direito, que proteja, em lugar de afligir os criminosos?

Se formos examinar o sistema penal das cidades ideais imaginadas por Thomas Morus e Campanella, veremos que Dorado Montero foi muito além. Ultrapassou mesmo o sistema da ironia e piedade de Anatole France e se aproximou do cristianismo sublimado das concepções penais de Tolstoi. Morus e Campanella talvez não tivessem tido a infelicidade de sofrer um acidente que os deformasse, como a Dorado Montero. Uma bela figura de homem, tendo de se arrastar a vida inteira como um coxo vulgar, podia ter-se dominado pelo complexo de inferioridade, deixando expandir o seu ressentimento em doutrinas penais sedimentadas de crueldade. Era, entretanto, um espírito superior que soube psicanalisar-se antes da grande expansão das doutrinas de Freud, surpreendendo o mundo científico pelo arrôjo de suas idéias humanitárias no campo do direito criminal.

Não fôra o destemor de Jiménez de Asúa em proclamar, sempre e insistentemente, o grande valor da obra do professor salmantino, e talvez ninguém mais se lembrasse das suas "Bases para un Nuevo Derecho Penal", inteiramente isentas de tôda e qualquer idéia de reação vingativa.

Não admira que a vingança constitua o fundo do direito penal moderno, como demonstram Ruiz-Funes e os citados ascritores americanos, uma vez que, tanto na "Utopia" de Thomaz Morus como na "Cidade do Sol" de Campanella, é a vingança que funciona através da justiça penal. Como homens que eram, não puderam os imaginosos criadores de sociedades perfeitas eliminar o crime. E, para combatê-lo, não conseguiram descobrir coisa melhor que um conjunto de reações, por via das quais se expande o instinto de vingança. 
"Na "Utopia" se encontra uma pena curiosíssima. A cobiça é o mais repugnante dos vícios, e, para lutar contra a mesma, é preciso criar nos homens o desprêzo pelas riquezas e pelos metais preciosos; por isso, a todos os que foram infamados pela prática de algum crime, penduram nas orelhas brincos de ouro, adornam os dedos com anéis de ouro, enrolam a garganta com colares de ouro e cingem a fronte também com coroas de ouro, visando envilecer o ouro e a prata. A virgindade das mulheres e dos homens é defendida, na "Utopia", com admoestação e castigos: o pai e a mãe em cuja casa se cometeu o delito ficam infamados, por não terem vigiado com a necessária diligência.

"Vejamos, porém, as penas pròpriamente ditas, começando pela de adultério. Castiga com a mais dura escravidão os profanadores do matrimônio. Se ambos os culpados são casados, os esposos inocentes que sofreram a ofensa, se quiserem, podem casar-se um com o outro ou com pessoa distinta, repudiando o adúltero. Se um ou outro dos ofendidos persiste no seu amor ao que tão mal se comportou, a lei não o impede, se quiser, de acompanhar na escravidão o condenado. $\mathrm{E}$ às vêzes acontece que, comovido o príncipe pelo arrependimento de um e pela firme constância de outro, chega a conceder a liberdade ao primeiro. Mas o reincidente é castigado com a pena de morte.

"Nenhuma lei fixa pena determinada para os delitos, competindo ao Senado estabelecê-las em cada caso, de acôrdo com a natureza das faltas. Os maridos castigam as suas mulheres e os pais os seus filhos, a menos que a infração seja tão grave que convenha, para a manutenção dos bons costumes, um escarmento público. Quase todos os crimes graves são punidos com a escravidão, castigo que consideram mais terrível para o delinqüente e mais vantajoso para o Estado do que apressar-se a matar o réu, privando-se dos benefícios do seu trabalho, e como exemplo que, por ser duradouro, afastará muitos outros da mesma senda delituosa.

"Mas os condenados que se mostram rebeldes ou recalcitrantes são mortos como animais indomáveis, que não 
podem ser contidos nem pelos cárceres nem pelas correntes. Não tira, porém, aos delinqüentes a esperança de verem os seus sofrimentos mitigados pelo sufrágio do povo ou pela benevolência do príncipe."

E Jiménez de Asúa, que é quem nos oferece êste resumo do sistema penal da "Utopia", mostra que não era mais brando o da "Cidade do Sol" do iluminado Campanella:

"Cada indivíduo é julgado pelo Mestre superior do seu ofício. Por isso, todos os primeiros artífices são juízes e castigam com o destêrro, com açoites, com a degradação, com a privação da mesa comum, com a proibição de freqüentar o templo e com a abstenção do comércio carnal.

"Quando o fato culpável é injurioso, é punido com a morte. Se a culpa foi voluntária e com reflexão, paga-se segundo a lei de talião, ôlho por ôlho, nariz por nariz, dente por dente. Se tiver havido rixa, sem premeditação, a sentença se abranda, mas não por ato do juiz, e sim pela intervenção do triunvirato...

"Não têm cárceres, mas apenas uma tôrre, onde encerram os inimigos e os revoltosos. Para evitar que a República seja maculada, não têm litores nem verdugos. $O$ condenado morre às mãos do povo, que o apedreja e mata. As primeiras pedras são arrojadas pelo acusador e pelas testemunhas. A alguns réus se dá o direito de escolher o gênero de morte. Êstes costumam rodear-se de sacos, cheios de pólvora, que, incendiando-se, os carbonizam, sendo assistidos nos últimos momentos por pessoas que os exortam a padecer resignadamente. Tôda a cidade se cobre de luto, e roga a Deus que aplaque a sua cólera, lamentando-se da necessidade de amputar um membro apodrecido da República. Também se esmeram em convencer o réu, com apuradas razões, de que deve aceitar e receber de bom grado a sentença capital. Caso isso não aconteça, não se executa a sentença; mas, se o delito cometido atenta contra a existência da República e contra Deus ou contra o magistrado supremo, a sentença é executada sem a mínima compaixão." ("El Criminalista", tomo IV, págs. 48-49, Buenos Aires, 1944.) 
Vê-se, portanto, que pregar a supressão da pena é ir além da "Utopia". Sómente a ultrapassaram os anarquistas, os místicos, como Tolstoi, e ironistas, como Anatole France.

Mas a escola de Dorado Montero, representada pelos valentes pregadores Jiménez de Asúa e Ruiz-Funes, e que reclama um tratamento protetor dos criminosos, encontra agora decidicio apoio no pragmatismo americano, na filosofia prática dos ianques, que vão formando coortes no combate à prisão e aos castigos, na depuração de todos os processos vindicativos, aconselhando a substituição das penas, especialmente a de prisão, por um tratamento que nada. tenha de castigo e que seja capaz de realizar um ideal educativo, que tão difìcilmente se concilia com a crueldade, inseparável dos regimes penitenciários.

O que é indispensável é depurar êsse tratamento, não apenas da idéia de vingança, que a doutrina penal já arredara, mas também do fundo de reação vindicativa, conservado pelo sistema penal moderno, como que subconscientemente, em tôdas as suas reações contra a criminalidade, de acôrdo com a demonstração de Ruiz-Funes:

"O delito provoca, nas consciências honestas, determinados sentimentos. Nesses sentimentos se encontra a origem da pena. A necessidade de dar uma satisfação adequada a tais sentimentos constitui a razão de ser da punição. Com essa reparação, a tranqüilidade atacada pelo delito se restabelece.

"Georges Vidal fêz uma classificação bem precisa e exata dêsses sentimentos. O delito suscita, em primeiro lugar, nas consciências individuais, um sobressalto, produzido pelo temor de que venha a repetir-se. Dêste sentimento essencial derivam outros. Para que o delito não se renove, convém que a pena produza uma verdadeira intimidação sôbre o réu. A coação impedirá o surto de possíveis atividades criminosas no delinqüente. E essa intimidação há de se estender aos demais, como verdadeira advertência coletiva, que aniquile nas consciências vacilantes 
todos os germes de uma provável conduta criminosa. A pena deve defender a sociedade tôda contra o crime, e há de ter um caráter de prevenção geral, quando formula ameaças, que impeçam qualquer ataque criminoso, e de prevenção especial, ao dirigir-se concretamente ao que já delinqüiu, para anular suas ações antijurídicas.

" $O$ delito desperta igualmente o horror e a repulsa ao delinqüente. $O$ seu ato encontra geral desaprovação. Denuncia, além disso, a falta de senso moral, comum a todos os homens pertencentes a um determinado tipo de civilização. Essa falha ética fere a consciência pública e engendra uma reprovação. O delinqüente é considerado como um anormal e, em conseqüência, como um dessemelhante. A pena é uma das formas de desaprovação coletiva do delito...

"Outro sentimento que desperta o delito é o desejo de vingança. Provoca uma verdadeira revolta da dignidade coletiva. Trata-se de uma indignação, que às vêzes assume formas incoercíveis, capazes de romper todos os freios inibitórios e de anular os poderes críticos. Expressões agudas dessa indignação gerada pelo delito são as reações brutais e convulsivas das multidões. $\mathrm{Na}$ origem dêste processo de desintegração moral encontra-se como que uma projeção dos sofrimentos infligidos pelo delinqüente à sua vítima. Estes sofrimentos, socialmente reproduzidos mediante um mecanismo interpsicológico de representações, podem conduzir ao desejo de se refletir e até de dar-lhes nova vida no próprio culpado, sob a ação do impulso expiatório. $O$ sentimento público que assim transborda se satisfaz, mais ou menos intensamente, com uma atividade vingativa. A vingança, em tal caso, apraz à coletividade e se explica como um impulso geral.

"Assinala Vidal que êsses sentimentos, passíveis de excessos, são perigosos, em razão de sua hipertrofia. As sanções que se inspiram exclusivamente nêles são exageradas e, por isso mesmo, injustas. A repulsa ao criminoso, quebrando os freios morais, obscurece a inteligência e per- 
mite que desabrochem instintos recônditos, que se expandem desmesuradamente, suprimindo tôda idéia de justiça." (Págs. 35-36.)

"No fundo da defesa social contra o delito, há uma corrente coletiva, que o legislador deve dirigir e purificar. Nessa corrente, atua sempre um sentimento de vingança. Libertá-la dêsse impulso obscuro e subconsciente constitui imperioso dever dos que legislam. Mezger afirma que o direito penal, como fenômeno social, visto de um plano elementar, se mostra instintivo e inconsciente, inspirado pelo sentimento primitivo da vingança. Esse sentimento não é, entretanto, em sua opinião, mais do que a projeção no mundo exterior de uma representação da personalidade, a qual, segundo Gerland, é logo superada pela ação racional da reflexão, que depura a pena de tôda influência vingativa, transformando-a em uma pena-fim." (Pág. 41.)

"A vingança, tradicionalmente usada como instrumento de proteção pessoal contra o inimigo exterior, reaparece hoje, segundo Alexander e Staub, e encontra sua expressão no caráter de represália atribuído ao castigo, em um despertar da brutal severidade primitiva, na maneira irracional de incluir um sofrimento inútil na pena e na sua execução.

"A expiação, como sacrifício de um homem nas aras de um deus ou de um poder cruel da mitologia, irritado e implacável, dificilmente se separa da idéia de vingança. É. preciso fazer sofrer ao que foi causa de uma dor e aplacar a ira, engendrada pelo delito, naqueles poderes obscuros que superintendem os nossos destinos.

"Alexander e Staub afirmam, com razão, que a história do direito penal manifesta sempre a aspiração de conseguir uma vitória do pensamento racional sôbre os fundamentos: instintivos e irreprimíveis da pena.

"A defesa social não é vingança social, afirma Florian. É preciso eliminar essa idéia, que conserva tantos vestígios no direito penal. É cruel, excessiva, aberrante e repugna ao sentimento humano. Não encontra fundamento na ne- 
cessidade. Com ela, segundo o mestre italiano, há de desaparecer também o conceito de que a pena deve conservar sempre e necessàriamente um conteúdo aflitivo.

“Represália, vingança e expiação são manifestações de sadismo e só quando socialmente puderem ser inibidos tais impulsos é que se conseguirá, como assinalam Alexander e Staub, dar ao sentimento de justiça uma plena e pura satisfação." (Págs. 47-48.)

"Vincenzo Lanza, que defende com generoso entusiasmo uma posição humanista no campo do direito penal, encontra no ímpeto emocional, produzido pelo mêdo ou pela cólera, a gênese psicológica da penalidade. Da cólera derivam a vingança, o prazer despertado pelo mal alheio, e o ódio.

"O desejo de castigar, segundo êsse penalista, vem a ser a transformação do mêdo e da cólera localizados pela ação das emoções simpáticas. O ódio ao criminoso se depura também pelo embate dos sentimentos sociais." (Pág. 57.)

"Durkheim chega a afirmar que a vingança pode constituir uma arma defensiva de algum valor, mas grosseira e caprichosa. Incapaz de possuir uma consciência dos serviços automáticos que presta, escapa a tôda regulamentação e se propaga pela ação difusa do acaso, pelo impulso de causas cegas que a deflagram, sem que nada possa moderar o seu ímpeto. É uma necessidade irracional de destruir que a impele, segundo a observação do grande sociólogo francês. É uma reação mecânica e sem finalidade, um movimento passional e ininteligente $\mathrm{e}$, ainda quando tenha a aparência de um ato de defesa, pela certeza de estarmos reagindo contra um mal, a ação vindicatória é instintiva e irreflexiva. Daí se explica que a vingança, nas formas punitivas da reação penal, represente o castigo pelo castigo, o sofrimento pelo sofrimento. Desprovida de uma preocupação finalista, atenta sòmente ao mal efetivamente sofrido ou a um perigo ocorrido, castiga até os seres inanimados e os inocentes, e não se detém com a realização de um objetivo 
eficaz, só se estancando pelo esgotamento da paixão que a desencadeou." (Pág. 62.)

"Para a psicologia, existe um complexo de vingança, que é ambivalente. E' integrado pelo prazer de ter dado satisfação à cólera e ao ódio e, por outro lado, pelo prazer igual de realizar um ato mau, anti-social e punivel, causando um dano. A ambivalência da vingança aparece também nas profundidades do inconsciente: deseja-se o ato violento, mas teme-se realizá-lo. Nessa luta entre o temor e o desejo, triunfa o desejo, que é o prazer; ou, então, a censura, impulsionada pelo temor, reprime a atividade vingativa. 0 desejo contido de vingança fica então instalado no inconsciente, esperando uma ocasião propicia para expandir-se no mundo exterior ou projetar-se no mesmo por meio de equivalentes. Esses desejos inconscientes se traduzem, às vêzes, por impulsos conscientes, cuja expressão vem a ser o perigo social. Este perigo social consiste na possibilidade de serem transgredidas determinadas proibições, fato que, reiterado, poderia dar lugar à dissolução da sociedade.

"Freud assinalou a identidade dos desejos recalcados no criminoso e nos que são encarregados de vingar a sociedade ultrajada. Quando um indivíduo consegue satisfazer um desejo reprimido, igual tentação sentem os membros da coletividade. Para refrear êsses desejos gerais, é preciso castigar a audácia do que agiu primeiro. O castigo proporciona aos que o impõem a ocasião de cometer, por sua vez, o mesmo ato impuro, cobrindo-o com o manto da expiação. A psicologia profunda descreve por esta forma o mecanismo genético da vingança, e sua complexidade.” (Págs. 65-66.)

"Para Florian, a vingança privada constitui um fato geral e constante entre os povos primitivos. Ressurge sempre na decadência dos Estados, segundo a observação de Salvioli, por exemplo, com a queda do Império romano ou na época das invasões." (Pág. 50.)

“ $E$ ' fácil compreender, com êstes antecedentes, qual é o conceito totalitário, com leves distinções de matiz, da justiça penal. A Rússia e a Itália têm seus códigos. 0 russo 
é um corpo de leis de que se aspirava suprimir os delitos em espécie, que passariam a constituir uma criação da consciência socialista do juiz; considera a criminalidade política a de maior gravidade e contra ela pronuncia penas severíssimas, em contraste com a benignidade da lei a respeito dos delitos naturais. Na Itália, o Código Penal, de inspiração clássica, aceita muitos princípios liberais, como o da legalidade; mas sanciona um número considerável de delitos com a pena de morte. Não obstante isso, conserva a aparência dos códigos penais das democracias.

"Na Alemanha, porém, a revolução no direito penal foi mais profunda. Passou-se a legislar por meio de ordenanças. Ordinàriamente, elas contêm poucos artigos e são os juízes que, ao aplicá-las, determinam o seu raio de ação, de acôrdo com o sentimento popular. Tudo é provisório e inseguro. Volvem aos princípios básicos do direito germânico: "o que quebra a paz perde a paz." Coloca-se o homem fora da lei. O delinqüente é o inimigo. A paz é a base da existência do Estado (a paz interna, bem entendido.) A luta contra o crime deve ser tão cruel como a guerra. O Estado, ao aplicar a lei penal, é como um soldado diante do inimigo. A pena não é um meio, mas a própria luta contra o delito: é um ato de heroísmo. E' preciso reprimir; mas cumpre também colocar-se preventivamente em atitude de ataque, que é sempre a melhor defesa. A pena tem como finalidade aterrorizar. Se o terror estiver presente no ânimo do criminoso, na hora da tentação, poderá resistir. Realizado o mal, o que se impõe não é a reforma do delinqüente, e sim a vingança. O corpo do homem assassinado clama por vingança.

"O conceito mais exato da pena, dentre os elaborados pelos técnicos da ciência penal que serviram de inspiração às construções do direito nacional-socialista, é o de van Gemminge, figura de relêvo nas novas construçõ̀es jurídicas autoritárias. O Eśtado deve aspirar com a pena, segundo êste autor, "a retribuição, por meio do sofrimento do agente, do mal pelo mal, ainda que dai não resulte proveito al- 
gum para a sociedade, e ainda quando isso represente um aniquilamento insensato."

"O direito é uma nova forma de vida. Corre no sangue, vive no povo. Não é instinto nem razão. E' alheio à lógica e à moral. O Professor Schinnerer, de Berlim, diz que o direito penal deve ser baseado no sentimento popular do justo e do injusto, acrescentando que a função da justiça penal consiste na aplicação de princípios estabelecidos pelo Código em função da reação da comunidade alemã contra os empreendimentos criminosos. A justiça deve estar de acôrdo com a conviç̧ão popular e em perfeita harmonia com a vontade do Fuehrer." (Págs. 215 a 217.)

"Rosenberg declara, como intérprete oficial, que o direito penal nacional-socialista é essencialmente popular, elaborado pelo povo e para o povo alemão, realidade distinta do Estado; realidade em que o Estado representa apenas a forma jurídica; uma realidade histórica, psicológica e moral... realidade criada pela comunidade de sangue e de solo. O direito penal novo - acrescenta o mesmo Rosenberg - é um direito de raça. E, assim, como observa Jones, passa-se do direito à biologia e desta à etnologia; contra as raças mais débeis se levanta, como direito do melhor quilate, tôda pretensão das mais fortes." (Pág. 217.)

Dai, mostra Ruiz Funes como puderam os juristas alemães elevar à categoria de direito tôda aquela série de desconchavos contra os judeus e outras raças coloridas, sem que, entretanto, manifestassem a mais mínima repugnância em aliar-se com os japonêses.

Dentre as reações reveladoras de um recrudescimento de impulsos sádicos de vingança, em sua forma primitiva, está a lei de castração, permitindo até a mutilação dos autores de atentados sexuais. " $E$ ' uma reminiscência do talião simbólico, que atingia com a pena o membro com que se havia cometido o delito." (Pág. 225.)

0 artigo $6 .^{\circ}$ da Ordenança de $1 .^{\circ}$ de agôsto de 1933 declara que "com a execução da pena deve-se fazer compreender ao condenado, de uma forma séria e duradoura, que tem 
de expiar suas transgressões contra a ordem jurídica do Estado, pela privação da liberdade, privação que há de constituir um mal sensível. $O$ temor de sofrer novamente o mal de uma execução dessa natureza, por novo delito, deve fazer-lhe sentir vivamente, pelo caráter rigoroso da execução penal, mesmo que seja um delinqüente não suscetível de readaptação moral, verdadeiros arrepios contra a tentação de cometer novos delitos." (Pág. 226.)

$E$ foi êsse recrudescimento do instinto de vingança, que passou a informar todo o direito penal nazista, a causa do conhecidíssimo incidente ocorrido no Congresso Penitenciário de Berlim em 1935, onde os representantes alemães quiseram negar à pena tôda e qualquer finalidade educativa ou de readaptação dos. delinqüentes à sociedade, tentando fazer prevalecer a fôrça numérica dêsses representantes sôbre as razões juridicas e de ordem moral opostas por quase tôdas as delegações estrangeiras.

Jiménez de Asúa, em um estudo recente sôbre o velho tema do fundamento do direito de punir, examina, de acôrdo com a classificação de Florian, as teorias absolutas, as teorias relativas e as teorias mistas quanto à finalidade da pena, e apresenta, por último, a doutrina de Dorado Montero:

"Com as doutrinas relativas de novo cunho, isto é, com a pena de fim plural, a tese absoluta do "jus puniendi" se converte em uma síntese, que alcança o melhor sentido na doutrina de Dorado Montero. 0 grande mestre e os que nos proclamamos seus discipulos, em vez de concitar esforços para evitar que o direito punitivo se esfacele, e de buscar novas fórmulas para mantê-lo de pé, deixamos que êsse direito se desnude e, no velho solar, limpo de escombros dos preconceitos, edificamos o direito protetor dos criminosos, que constitui uma negação do multissecular "jus puniendi", no sentido estrito de direito de impor castigos; mas não caimos na antitese anarquista, porque proclamamos o direito do Estado de promover o tratamento dos violadores da norma. 
"Esta doutrina do direito protetor dos criminosos é, segundo pensamos, a verdadeira escola espanhola, de moderna concepção. Os ideais do grande mestre salmantino encontram hoje refôrço psicológico na doutrina da psicanálise e da psicologia profunda." (Pág. 59.)

Ninguém põe em dúvida que o cárcere do antigo regime constituía um instrumento de martírio. A literatura universal está cheia de descrições impressionantes das lôbregas prisões, construídas com o desprêzo consciente de todos os preceitos da higiene e com o propósito de provocar os maiores padecimentos aos encarcerados.

Sobreveio, porém, a campanha humanitária, com a publicação, em 1774, do célebre livro de John Howard, "State of Prisons." Essa obra teve, no campo da ciência penitenciária, influência igual à de Beccaria, que aparecera dez anos antes, na esfera do direito penal.

Assim, a reforma do direito penal substantivo teve como corolário a reforma da organização penitenciária. Começaram a aparecer os cárceres-modelos, visando não só a segurança como também a preservação da saúde dos presidiários. Já a Constituição do Império, no Brasil, dispunha, em seu art. 179, n. 21: “As cadeias serão seguras, limpas e bem arejadas, havendo diversas casas para separação dos réus, conforme suas circunstâncias e a natureza dos crimes."

Nos Estados Unidos, o movimento de humanização da pena encontrou campo propício na Pensilvânia. Criou-se aí o sistema celular, visando a reforma pelo isolamento. Veio depois o sistema de Auburn. Celebrizaram-se os grandes diretores Elam Lynds (que aliás não primava pela brandura), Osborne e Brockway, êste no famoso reformatório de Elmira. E, assim, durante mais de século e meio, gozaram de extraordinário prestígio os estabelecimentos americanos. E novos e mais suntuosos reformatórios continuam a ser ali edificados, destacando-se a Penitenciária de Jackson, em Michigan, para 6.000 homens, e que custou 8 milhões de dólares, a de Graterford, na Pensilvânia, para 3.200 sentenciados, custando mais de sete milhões e 
meio, a de Ática, em Nova York, para 2.125 habitantes, com um custo de nove milhões, e a de Stateville, no Illinois, que ficou em dez min̄nões (Barnes e Teeters, pág. 651.)

Numa das conferências aqui pronunciadas sôbre a reforma penitenciária em São Paulo, tratei de um novo movimento de humanização que se nota na penologia americana. Mostrei que, para reagir contra o aumento da criminalidade, que se verificou depois da guerra passada, muitos Estados adotaram uma política de exacerbação das penas. Suprimiram o livramento condicional e tornaram o regime carcerário mais severo. As pinitenciárias se encheram de tal forma que se tornou impossivel manter a disciplina, verificando-se revoltas, que tiveram de ser reprimidas a metralhadora. E a criminalidade, em vez de diminuir, aumentou de maneira espantosa.

Diante disso foi que os criminologistas americanos se puseram em campo, para estudar, com aquela insuperável capacidade de organização, o fenômeno da criminalidade em suas causas, pesquisando também os remédios adequados. $\mathrm{E}$, de 1935 para cá, êsses estudos se vêm orientando no sentido de criar uma nova penologia, em que se substitua o castigo pelo tratamento e a prisão por estabelecimentos de ensino e de trabalho.

Em 1941, Evans Wood e Barker Waite, professores da Universidade de Michigan, e autores do livro "Crime and its Treatment", concluíam um longo capitulo de elevada filosofia sôbre a punição, com êstes conceitos:

"A base psicológica da pena encontra-se no mêdo e no ressentimento provocados na comunidade social contra aquêles que violaram as leis, de maneira a constituírem um perigo para a segurança pública. São êsses sentimentos que exigem retribuição. Conquanto tenhamos mostrađo a ineficácia da justiça retributiva do ponto de vista da defesa social, é duvidoso que a mesma venha a ser inteiramente abandonada, por causa dessas reações da natureza humana. O máximo que uma penologia mais científica e mais humana pode fazer é pôr em cheque as reações mais ferozes do 
público, dirigindo as suas vistas para métodos científicos de reforma do criminoso. Finalmente, o espirito da reforma deve ir além do criminoso, procurando o reajustamento das condições sociais ambientes, que exercem decisiva influência no surto da criminalidade. Uma sociedade firmemento empenhada em remover os obstáculos ao normal desenvolvimento humano há de gradualmente relegar a inteiro descrédito os métodos vingativos de punição. E então, com o eclipse das práticas dominantes de castigo, dar-se-á o desenvolvimento de métodos mais esclarecidos de defesa social." (Arthur Evans Wood e John Barker Waite, "Crime and its Treatment", págs. 485 e 486.)

Barnes e Teeters, professores da Temple University, de Filadélfia, nos seus "Novos Horizontes da Criminologia", obra de mil e tantas páginas, mostram-se mais decididos, senão mesmo radicais, na proscrição do castigo, das penas pròpriamente ditas, como arma ou meio de defesa social. Pelas citações dêsses e de outros autores americanos, vê-se que a falência das penitenciárias, como instrumento de reforma dos delinqüentes, foi decretada nos Estados Unidos por um livro, de extraordinária repercussão, da autoria de Sheldon e Eleanor Glueck, "A Vida de Quinhentos Criminosos" ("Five Hundred Criminal Careers"), editado em 1930.

Num capítulo sôbre a crueldade e inutilidade da prisão moderna, aquêles escritores dão conta de processos empregados nas prisões de hoje, com o objetivo de punir os reclusos, que são tão horripilantes como os tormentos da Idade Média e da época do absolutismo.

Frank Tannenbaum, professor da Universidade de Colúmbia, prefaciando "Os Novos Horizontes da Criminologia", diz que o crime é um fenômeno tão permanente como a própria sociedade: "Crime is eternal - as eternal as society." Seria uma quimera a pretensão de extinguir êsse fato social. Reconhece, entretanto, a necessidade de lutar contra êsse mal, para atenuá-lo tanto quanto possível. Acha que os autores do livro fizeram muito bem em dividir os criminosos em profissionais e acidentais. Quanto aos pri- 
meiros, a segurança da sociedade exigiria a sua segregação em estabelecimentos com alguma coisa dos atuais presídios. Mas, em relação aos ocasionais, nada pode haver de mais contraproducente do que atirá-los num lugar como êsses, pretendendo educá-los para a liberdade pelo processo anacrônico de privação dessa mesma liberdade. E diz que, mesmo em se tratando de criminosos profissionais, a experiência tem sido má, e que "o repúdio à prisão como principal e quase único método de tratamento dos criminosos é a única posição lógica a ser tomada. A prisão não resolverá o problema da criminalidade - ela sòmente o agrava, aumentando o número dos que vêm a adotar uma conduta ilegal como meio de vida."

Não é apenas pela possibilidade, que a prisão moderna oferece, de se renovarem aquelas práticas negregandas da Inquisição e do "antigo regime" que Barnes e Teeters a estigmatizam com adjetivos tão eloqüentes como os de Howard e Beccaria: é principalmente porque a prisão produz uma desintegração da personalidade humana. Escrevem êles:

"A despeito das brutalidades da administração penitenciária, da perpetuação dos castigos corporais e da conservação da cela escura, na disciplina da prisão moderna; não é a crueldade o seu aspecto mais deplorável, e sim a desintegração da personalidade dos reclusos. Geralmente, entendemos que a prisão representa um enorme progresso em relação ao sistema da transportação ou degrêdo e das penas corporais. Mas, quando examinamos a natureza das instituições penais e a disciplina da prisão através da última centúria, somos levados a duvidar se a prisão contemporânea representa na realidade um melhoramento sôbre os pèlourinhos, os troncos e o degrêdo. Nenhuma dessas penalidades contribuía tanto para a degradação e desintegração da personalidade do indivíduo. Ele era humilhado, mas não estigmatizado "in perpetuum" pela experiência da prisão. As atuais instituições de pena e reforma quase que invariàvelmente tendem a tornar o individuo muito mais perigoso para a sociedade do que era antes da reclusão. 
“Teòricamente, a prisão pode ser uma excelente instituição para a reforma do criminoso, mas à luz dos seus métodos práticos e da sua hodierna atuação talvez nada de mais ineficaz e vicioso possa ser concebido, como método de proteção da sociedade, para livrá-la das depredações das classes anti-sociais. Quase tudo quanto pode contribuir para solapar e desmoralizar a personalidade humana se encontra nas prisões de hoje e nos métodos contemporâneos de administração penal.

“A questão fundamental está em saber se devemos punir os condenados ou reformá-los, para que se tornem bons cidadãos. As duas coisas não podem ser obtidas ao mesmo tempo. Castigo e regeneração não podem ser geminados no mesmo sistema. A prisão hodierna é um lugar admirável para infligir castigos brutais, tanto mentais como físicos. Mas é o último lugar do mundo em que se poderão criar e desenvolver influências tendentes à reforma. Como notamos, em "Five Hundred Criminal Careers", os Drs. Sheldon e Eleanor Glueck verificaram que, de quinhentos liberados do Reformatório de Massachusetts, cêrca de oitenta por cento, cinco anos depois, não estavam reformados. A percentagem de reforma, na maioria das prisões estaduais, é ainda menor...

"Nossas instituiçôes penais não sòmente deixam de reformar o criminoso, como se transformam em verdadeiras escolas do crime." (Págs. 598 e 599.)

Tratando das concepções penais de Tolstoi, escreve Dorado Montero:

"De tôdas as manifestações da violência, aplicada em nome da justiça, o cárcere é uma das que provocava maior indignação a Tolstoi. Não acreditava que as prisões tivessem função alguma, pelo menos tolerável, a realizar. Preferiria os castigos corporais, e até mesmo a pena de morte, pois estas formas de penalidade lhe pareciam "verdadeiramente razoáveis", porque ao menos sua aplicação teria um objeto, acrescentando, porém, que tanto uns como outra, "graças à suavidade dos costumes, caíram em desuso." Em 
compensação a casa de martírio de hoje é cruel e sem objetivo algum."

Mas, hão de perguntar, com o mesmo Dorado Montero:

"Que fazer então dos maus, dos criminosos, dos perturbadores da ordem?"

Poderíamos, diante da realidade apavorante dêste mun. do convulsionado, no fim de uma luta homérica para o restabelecimento do direito e da liberdade, mas em que assistimos ao linchamento de criminosos de guerra, dar a resposta de Tolstoi? Que se há de fazer dos maus?

"Castigá-los?

"Não.

"Perdoá-los?

“Sim, e perdoá-los até setenta vêzes sete; tratá-los como a irmãos, segundo o ensinamento de Cristo."

Isso seria, evidentemente, desconhecer a natureza humana, como ponderam Wood e Waite. Mas, entre castigar e perdoar, que seriam duas atitudes negativas, temos um largo campo de ação no tratamento dos que delinqüiram e, dos possíveis delinqüentes. E tanto a medicina como a pedagogia progrediram bastante, para fugir da dor e do prazer inebriante, permitindo arejar os estabelecimentos de reforma com verdadeiros preceitos de higiene física e mental. 